\title{
Analyzing strange sounds during night
}

\author{
Joachim T. Maurer
}

Published online: 23 September 2010

(C) Springer-Verlag 2010

Sleep medicine is a fascinating field of research and clinical medicine. Many (more or less) strange phenomena during sleep have been described: Body rolling, leg movements, teeth grinding, and many more. Some of them have become an own diagnosis. In every case, the proper characterization of the new phenomenon is the first step of research if its pathophysiology and etiology shall be elicited. Sound production during sleep is such a phenomenon. Sounds during sleep mainly bother the bed partner whereas the sleeper himself may not necessarily be harmed. There are various sounds during sleep. Snoring was the first sound investigated thoroughly. Recently, Herzog et al. were able to classify snores according to their periodicity and their peak intensity as obtained by fast Fourier transformation. Using this tool, they could distinguish primary snoring, upper airway resistance syndrome, and obstructive sleep apnea [1]. Long before, Schäfer attributed low frequency snores to the soft palate and high frequency snores to the tongue base. He considered this tool being suitable to predict success of uvulopalatopharyngoplasty better [2]. The investigations were driven by the idea of simplifying the detection of sleep apnea and improving treatment success.

Nocturnal groaning has been described in 2001 for the first time. The second edition of the International Classification of Sleep Disorders of 2005 included nocturnal groaning as "Catathrenia" in the group of parasomnias. It is described as an expiratory sound of up to more than $40 \mathrm{~s}$. It seems to bear

\footnotetext{
J. T. Maurer $(\triangle)$
}

Department of Otorhinolaryngology, Sleep Disorders Center, University Medicine Mannheim, Medical Faculty Mannheim of the Ruprecht-Karls-University Heidelberg,

68135 Mannheim, Germany

e-mail: Joachim.maurer@umm.de no harm to the patient but may disturb the bed partner. In particular, it is rare and therefore difficult to investigate. In this context, one may raise the question: Is it really worth investigating nocturnal groaning further? Is it worth putting money and labor into it? Are there not more important "real" diseases meriting this input? There would be a negative answer for sure if a cost-benefit analysis was performed. However, there are many open questions. First of all, it is still unclear whether the groaning sound has its origin in the pharynx or larynx, in particular at the level of the glottis. Some sleep specialists blamed catathrenia being a type of expiratory snoring.

Fortunately, curiosity is often stronger than a negative cost-benefit analysis of funding agencies. Iriarte et al. have to be congratulated because they were so curious to investigate catathrenia further without any financial support. In their work, "Sound Analysis of Catathrenia: A Vocal Expiratory Sound" published in this issue of Sleep and Breathing, they compared snores and groaning by sound analysis. They could clearly show that catathrenia is generated at the level of the glottis and nowhere else. Therefore, it may not be mixed with expiratory snoring which, of course, may exist as well in the same patient.

The scientific drive in sleep medicine is very high and we are glad that Sleep and Breathing is able to present the fruits of curiosity to the readers.

\section{References}

1. Herzog M, Schmidt A, Bremert T, Herzog B, Hosemann W, Kaftan H (2008) Analysed snoring sounds correlate to obstructive sleepdisordered breathing. Eur Arch Otorhinolaryngol 265:105-113

2. Schäfer J (1989) How to identify the soft palate snorer and predict success of UPPP. Laryngol, Rhinol, Otol 68:290-295 